\title{
A CONCEPTUAL ESCAPE FROM THE PERILS OF UNIVERSAL GRAMMAR
}

\author{
JOEL PARTHEMORE \\ Joel.parthemore@his.se \\ Department of Cognitive Neuroscience and Philosophy \\ University of Skövde, Skövde, Sweden
}

Noam Chomsky's notion of an innate universal grammar (see e.g. Hauser \& Chomsky, 2002; Chomsky, 1976) is known to be problematic, not least for identifying recursion as the defining aspect underlying human language, given the extremely limited use of recursion in known languages and ongoing claims (see e.g. Evans \& Levinson, 2009) that some languages lack recursive capacity altogether. Far more serious, perhaps, is the sense that universal grammar is delivered by a priori fiat and empirical evidence is all but completely lacking. As Evans and Levinson argue, few aspects of language, indeed, are, on closer examination, in any meaningful sense universal, which might seem to point against universal biological foundations. Although a couple decades ago Chomsky's views on language still dominated the field, recent years have seen such notions as universal grammar being increasingly called into question.

Whether taking the form of a universal grammar or not, innate linguistic capacity has another consequence that might seem undesirable: by suggesting that syntactically and grammatically structured language is uniquely human, it risks creating an absolute divide between human beings and other terrestrial species - a number of which, as the burgeoning field of comparative cognition has revealed over the past couple decades, show complex cognitive abilities, including abilities, such as spontaneous tool use (e.g., Smith et al., 2012), planning for future deception (Osvath \& Karvonen, 2012), and mirror selfrecognition (Gallup, 1977; Prior et al, 2008; Plotnik et al, 2006; Reiss \& Marino, 2000), that were previously thought strictly to be human. Some, including this author (Parthemore, 2013a, 2013b) have argued that commitment to an absolute divide is a relic of religious traditions, and that understanding what human beings have in common with other species is prerequisite to understanding how human beings are unique.

Unfortunately if one argues, as Daniel Dennett sometimes appears to (1995, 2008) and someone like Zoltan Torey $(2009: 46,123)$ does quite explicitly, that 
human-style language is necessary for having a mind (at least in anything remotely like the human sense), then either language is a prerequisite for mind (and for such characteristically "higher" mental capacities as cognitive agency) or the two must arise simultaneously. Either way, an innate language capacity of one form or another - presumably delivered by evolution - seems all but impossible to avoid. Language is not something that human beings worked out collectively; it is effectively hard-wired in. Such a conclusion will be hard to accept for anyone hewing more to the empiricist than the rationalist tradition.

Such philosophers as Albert Newen, Andreas Bartels (Newen \& Bartels, 2007), and Colin Allen (1999) offer an alternative - one that resonates well with comparative cognition research. Conceptual agency ${ }^{1}$ exists along a continuum where it is appropriate to attribute some substantial degree of it so soon as an agent, through its behavior, exhibits a capacity to categorize the world, create novel categories, apply those categories to new circumstances, and - most importantly, perhaps - express surprise when the resulting expectations get violated. None of that prima facie requires language. What language does (see e.g. Parthemore, 2014) is not to make conceptual agency possible in the first place but allow pre-existing concepts to be contemplated on much more abstract levels and new, abstract concepts to be created that were not previously possible - all of which allows the agent to step further back from the present moment and engage in longer and longer ranging mental time travel (MTT). That is to say that the Bischof-Köhler Hypothesis promoted by Thomas Suddendorf and Michael Corballis (e.g., 2007) is wrong - but only for the absolute divide it creates, not for its intuition that there is something unique about human MTT.

Of course if one views conceptual agency as existing along a continuum then one can, and should, argue about where to draw the line even as one should probably be prepared to shift that line depending on the present context of discussion: that is to say, the line should be pragmatic, not absolute. Viewing conceptual agency in this way is shown to fit in nicely with recent discussions from e.g. Merlin Donald (2001, 1993), Jordan Zlatev (2005; Zlatev et al, 2005) and others suggesting that mimesis (roughly, systematically structured imitative behavior) is one of the necessary steps, both ontogenetically and phylogenetically, on the road to language as a facility that arises naturally out of a cultural context, beginning from episodic memory (itself already conceptually structured), rather than anything innate. As Donald writes (1998:185): "humans are undoubtedly unique in their spontaneous invention of language and symbols; but, as I have argued elsewhere... our special advantage is more on the production side than on the conceptual side of the ledger. Animals know much more than they can express."

\footnotetext{
${ }^{1}$ Concepts may be understood here either as the building blocks of systematically and productively structured thought, or the abilities by which certain agents cognize in a systematic and productively structured fashion.
} 


\section{References}

Allen, C. (1999) Animal concepts revisited: The use of self-monitoring as an empirical approach. Erkenntnis, 51(1): 33-40.

Chomsky, N. (1976) On the nature of language. Annals of the New York Academy of Sciences, 280: 46-57.

Dennett, D.C. (1995) Animal consciousness and why it matters. Social Research, 62: 691-710.

Dennett, D.C. (2008) Kinds of Minds: The Origins of Consciousness. Basic Books.

Donald, M. (2001). A Mind So Rare: The Evolution of Human Consciousness. London: W.W. Norton.

Donald, M. (1998) Material culture and cognition: Concluding thoughts. In Renshaw, C. \& Scarre, C. (eds.), Cognition and Material Culture: The Archaeology of Symbolic Storage. McDonald Institute for Archaeological Research.

Donald, M. (1993) Origins of the Modern Mind: Three Stages in the Evolution of Culture and Cognition. Harvard University Press.

Evans, N. \& Levinson, S.C. (2009) The myth of language universals: Language diversity and its importance for cognitive science, Behavioral and Brail Sciences, 32(5): 429-448.

Gallup, G.G., 1977. Self recognition in primates: a comparative approach to the bi-direction properties of consciousness. American Psychologist, 32(5): 329338.

Hauser, M.D., Chomsky, N. \& Fitch, W.T. (2002) The faculty of language: What is it, who has it, and how did it evolve? Science, 298(5598): 15691579.

Newen, A. \& Bartels, A. (2007) Animal minds and the possession of concepts. Philosophical Psychology, 20(3): 283-308.

Osvath, M. \& Karvonen, E. (2012) Spontaneous innovation for future deception in a male chimpanzee. PloS one, 7(5): e36782.

Parthemore, J. (2014) The case for protoconcepts: Why concepts, language, and protolanguage all need protoconcepts. Theoria et Historia Scientiarum, 11: 159-178.

Parthemore, J. (2013a) The 'final frontier' as metaphor for mind: Opportunities to re-conceptualize what it means to be human. In Dunér, D., Holmberg, G., Parthemore, J. \& Persson, E. (eds.), The History and Philosophy of Astrobiology: Perspectives on the Human Mind and Extraterrestrial Life (67-92), Cambridge Scholars Publishing.

Parthemore, J. (2013b) Reappraising the relationship between concepts and language: The view from philosophy of mind and cognitive science. Paper presented at SALC IV (Scandinavian Association for Language and Cognition), 13-15 June 2013, Joensuu, Finland. 
Plotnik, J., de Waal, F., Reiss, D. (2006). Self-recognition in an asian elephant. Proceedings of the National Academy of Sciences, 103(45): 17053-17057. http://www.pnas.org/content/103/45/17053 (accessed 2018-01-26).

Prior, H., Schwarz, A., Güntürkün, O. (2008) Mirror-induced behavior in the magpie (pica pica): evidence of self-recognition. PLoS Biology, 6(8): e202. http://dx.doi.org/10.1371/journal.pbio.0060202

Reiss, D., Marino, L. (2000) Mirror self-recognition in the bottlenose dolphin: a case of cognitive convergence. Proceedings of the National Academy of Sciences, 98(10): 5937-5942.

Smith, B.P., Appleby, R. \& Litchfield, C.A. (2012) Spontaneous tool use: An observation of a dingo (Canis dingo) using a table to access an out-of-reach food reward. Behavioural Processes, 89(3): 219-224.

Suddendorf, T. \& Corballis, M.C. (2007) The evolution of foresight: What is mental time travel, and is it unique to humans? Behavioral and Brain Sciences, 30(3): 299-313.

Torey, Z. (2009 [1999]) The Crucible of Consciousness: An Integrated Theory of Mind and Brain. MIT Press.

Zlatev, J., Persson, T. \& Gärdenfors, P. (2005) Mimesis: The "missing link" in human cognitive evolution. Lund University Cognitive Studies. http://www.lucs.lu.se/LUCS/121/LUCS.121.pdf (accessed 2018-01-26).

Zlatev, J. (2005) What's in a schema? Bodily mimesis and the grounding of language. In Hampe, B. \& Grady, J.E. (eds.) From Perception to Meaning: Image Schemas in Cognitive Linguistics. Walter de Gruyter. 